\title{
Figuring ubicomp (out)
}

\author{
Xaroula Charalampia Kerasidou ${ }^{1}$
}

Received: 9 February 2015/Accepted: 19 December 2016/Published online: 1 March 2017

(c) The Author(s) 2017. This article is published with open access at Springerlink.com

\begin{abstract}
This paper explores ubicomp as a configuration that comprises three key figures: ubiquitous computing as a name and a term, Mark Weiser who came to be identified as the father of ubiquitous computing, and finally the temporalities folded within ubicomp's 'vision'; all three figures tightly interwoven under the phrase, Weiser's vision of ubiquitous computing. By unpacking each figure and exposing the processes that hold ubicomp together, this paper makes visible the frictions and contradictions that ubicomp folds within it, while, at the same time, it attends to the practices that help the whole configuration to circulate, become dominant and productive. The aim is to destabilise and denaturalise the reductive dominance of ubicomp's origin story and attend, instead, to its multiple and messy nature and (hi)stories in order to open up the ways that it can be reconfigured differently.
\end{abstract}

Keywords Ubiquitous computing · Configuration · Figuration $\cdot(\mathrm{Hi})$ stories $\cdot$ Feminist STS

\section{Introduction}

Greenfield proclaimed at the beginning of his book: 'Thesis 01: There are many ubiquitous computings' [14], a plurality that he attempts to explain away with the help of the parable of the six blind men trying in vain to identify an elephant, each feeling a different part of its enormous body ([14], see also [31]). Yet it has always been rather questionable whether there is this one elephant, this one

Xaroula Charalampia Kerasidou

xaroulakerasidou@gmail.com

1 Department of Sociology, Bowland North, Lancaster University, Lancaster LA1 4YN, UK ubiquitous computing, that one can ultimately define and identify in its totality ${ }^{1}$ leading one to ask, how can one write the history, this one tale, of such an elusive thing?

Feminist STS (science and technology studies) ${ }^{2}$ helps us find a way out of such conundrums by advocating a shift away from traditional ontological understandings of independent, prefigured entities and epistemological questions of reference-what is ubiquitous computing? What is the history of ubiquitous computing?-towards messy figures, stories and questions of relational processes-how is ubiquitous computing figured in particular (hi)stories, practices and knowledges?

Ubiquitous computing is multiple and messy and done differently in different sites and different stories (see also [9]). As this paper will demonstrate, this multiplicity and messiness is worked in such ways as to get folded into and hidden away. The stories of the multiple and, sometimes contradictory, ubiquitous computings, in the plural, get sterilised, reduced and almost solidified around the one dominant story and history of the founding father and the ordered past and future. This process then results in a configuration sturdy enough so as to be easily and readily reproducible, and one that can become the basis for other stories, hence furthering its dominance.

\footnotetext{
${ }^{1}$ Weiser himself would say no, and interestingly he directs us away from ubiquitous computing as a singularity. As we will see later in this paper, already before his death in 1999, he had identified two homonymous yet different things under the name ubiquitous computing. One was his own vision, and the other was what 'they' had turned it into (see [11]). These two objects were so different that, apparently, the difference led Weiser to discomfort and frustration, and even to an effort to change the name of his vision (see [20]).

2 This is the term Suchman [36] uses to loosely identify a body of scholarship that has manifested itself at the fertile interconnections of a range of disciplines and traditions, such as feminist and postcolonial scholarship, science and technology studies, cultural studies, cultural anthropology [see, for example, 5, 16-19, 21, 28, 35].
} 
Employing the methodological tool of configuration [38], this paper seeks to intervene to this process by bringing some of this messiness and multiplicity to the fore.

According to Suchman, configuration 'is a device for studying technologies with particular attention to the imaginaries and materialities that they join together' [38] which has at its heart the concept of figuration. Figuration is a methodological, descriptive tool, developed most explicitly within feminist cultural studies of science, which seeks to both unpack the domains of practice and significance that are built into each figure, and articulate the semiotic and material practices involved in the making of worlds [5]. In other words, figuration provides the means to attend to the dual process through which the figure is produced and brought into being (the figure as an effect) at the same time as, in its turn, it brings a particular version of the world into being (the figure having effects).

I take the configuration of ubicomp to comprise three main figures: ubiquitous computing as a term, Mark Weiser who came to be identified as the father of ubiquitous computing, and finally the temporalities folded within its 'vision', all captured in the much circulated and recognisable phrase, Weiser's vision of ubiquitous computing; each one a different figuration, yet all of them tightly interwoven in this one configuration so that one can never travel far without the other. By closely following and attending to the stories that ubicomp tells about its own origins, histories and futures, this paper 'unpacks' each figure of the configuration, exposing the processes that hold it together and making visible the frictions and contradictions that it folds within it. My aim in doing this is not to undo the configuration, but actually to bring it to sharp focus. Or else, to ground it in specific sociomaterial imaginaries and practices, as Suchman suggests [38], and expose the labour and effort that is needed to make it work. This way, I seek to destabilise the reductive dominance of ubicomp's origin story and attend to its multiple and messy nature and its multiple and messy (hi)stories.

\section{Ubiquitous computing: what's in a name}

In contrast to popular belief, the term that Mark Weiser coins in his seminal paper 'The Computer of the 21st Century' is not ubiquitous computing, but embodied virtuality. ${ }^{3}$ Nevertheless, it is the former that has gained greater visibility, even though it was never introduced as such. The word ubiquitous,

\footnotetext{
3 The term embodied virtuality appears in the first page of the paper, when Weiser stresses the differences between his ideas and virtual reality; a project which had captured the imagination of the technoenthusiasts of the time. As he writes:

$[\mathrm{T}]$ he opposition between the notion of virtual reality and ubiquitous, invisible computing is so strong that some of us use the term "embodied virtuality" to refer to the process of drawing computers out of their electronic shells [43].
}

as a descriptive adjective, makes several appearances right from the beginning of the paper, while the phrase ubiquitous computing makes its first appearance later, not in the text, but in the caption of the paper's first figure which depicts Weiser and his colleagues sitting casually in one of PARC's meeting rooms surrounded by a range of new devices.

Still, regardless of its frequent use in the paper, Weiser appears rather unsure about the word ubiquitous. Towards the end of the Scientific American paper one catches a glimpse of his doubts when in his presentation of a futuristic scenario of life with ubiquitous computing, he gives us the following scene.

A blank tab on Sal's desk beeps and displays the word "Joe" on it. She picks it up and gestures with it toward her live board. Joe wants to discuss a document with her, and now it shows up on the wall as she hears Joe's voice:

I've been wrestling with this third paragraph all morning, and it still has the wrong tone. [...]

I think it's this term 'ubiquitous.' It's just not in common enough use and makes the whole passage sound a little formal. Can we rephrase the sentence to get rid of it? [43]

Regardless of its rather humble and uncertain beginnings, the phrase ubiquitous computing prevailed. And while the newly introduced term embodied virtuality was generally forgotten, the phrase ubiquitous computing acquired a new life. No longer only a descriptive phrase, it became a term on its own right. Actually, it became more than a term, or the name of a specific technological project. With work and effort, it sought to become a vision for a new way of life, or, as Rich Gold whose role was instrumental to this transformation puts it, it sought to become a 'cult' and a 'philosophy'. As he writes of his part at Xerox PARC:

I had two different tasks within the heady world of

Ubiquitous Computing. The first was to program and

to build prototypes. But the other task was to construct a philosophy. A Ubi-Comp Cult [14].

Gold seems to have proved rather successful in his task and so in 1994 WIRED magazine published a feature by Howard Rheingold with the title 'PARC is back' and the subtitle 'After fumbling the future, ${ }^{4}$ Xerox PARC is back

\footnotetext{
${ }^{4}$ This refers to the story that although Xerox PARC was the first to develop the personal computer in 1973, Xerox, the parent company, failed to understand the potential of PARC's work and ignored its technological achievement. It took almost a decade for the first successful commercial expressions of the personal computer to appear under the banners of companies such as IBM and Apple giving Xerox 'a reputation for "fumbling the future", and PARC for doing brilliant research but in isolation from the company's business' ([4], see also [33]).
} 
with a visionary new director, bright researchers, and amazing new technology'. The article introduces Mark Weiser, the new director of PARC's Computer Science Laboratory and his vision leaving little doubt regarding the importance of this ubicomp vision and the laboratory's work.

PARC teams are way beyond "fumbling the future." They are inventing the future again. But this time they are reinventing their understanding of how to invent the future, as well. There is a sense that they are onto something new, that instead of extending the old computer revolution into new widgets and gadgets, they are at the dawn of a whole new [...] revolution [30].

The idea that ubiquitous computing is somehow different, something more profound than any 'old computer revolution' which focuses on 'new widgets and gadgets' is one that makes several appearances, and becomes instrumental in how PARC sought to figure ubicomp. Indeed, in the Scientific American paper where Weiser first publicised his ideas, he presented three projects within the ubiquitous computing programme, the "first experimental "ubi-comp" system', as he earlier called them, which resulted in three new devices. ${ }^{5}$ Yet, it is not these 'new widgets and gadgets' that compel people like Rheingold to celebrate ubicomp's exceptionalism and proclaim that PARC is 'reinventing [its] understanding of how to invent the future' [30]. Weiser and his PARC colleagues are keen to steer attention away from the technological devices and in a different direction, as they claim, towards people themselves.

Figuring ubicomp as an essentially human-centred approach, Weiser and his colleagues construct a story of dualisms that is based on the concept of invisibility. Down with the old, machine-centred, complex and demanding personal computer. Up with the new, invisible, humancentred ubiquitous computing that takes the focus away from the cumbersome machines and back to the people and their interactions. Or, in its most simplistic and rather caricatured version (as it wilfully ignored the technical side of ubicomp itself), down with the machines and the technical, and up with people and the social. In Weiser's words:

[...] Machines that fit the human environment instead of forcing humans to enter theirs will make using a

\footnotetext{
5 These were a large wall-display program, later known as the LiveBoard and commercialized by Xerox in a subsidiary called LiveWorks, the book-sized ParcPad, later called the MPad, and the palm-sized ParcTab. These devices were supported and augmented by the Active Badge, a location tracking device developed originally for Olivetti Cambridge research laboratory by Roy Want who then joined PARC.
}

computer as refreshing as taking a walk in the woods [43].

This construction of an opposition between cumbersome grey boxes, on the one hand, and invisible, ubiquitous computers that are only there to facilitate and support human interactions, on the other, allows people like Rheingold [30] or, a decade later, Galloway [11], to assert that the intellectual origins and inspiration for ubiquitous computing lie in the social and cultural rather than the technical side of PARC's research.

The evocation of the intellectual foundations of ubiquitous computing through the concept of invisibility becomes central in figuring ubicomp as different and profound. In the Scientific American paper, Weiser summons the help of a range of thinkers, philosophers and psychologists, such as Herbert Simon, Michael Polanyi and Martin Heidegger, along with PARC's director, John Seely Brown, who through a neat rhetorical device are all made to support Weiser's own key premise; namely, the premise that invisibility, a key characteristic of his vision of ubiquitous computing, is 'a fundamental consequence not of technology but of human psychology' [43]. In other papers, it is not so much philosophers and psychologists, but anthropology, the social sciences or the humanities that are being mobilised in two ways - as the inspiration behind Weiser's ideas of invisible machines [45-48, 51] providing the foundation or the backdrop against which we are instructed to read ubicomp's endeavours to fulfil its goal, but also as the invaluable resource that can provide a novel and important insight into people's lives 'exposing the otherwise invisible' [47].

References to the humanities and social sciences as resources that can be put to good use within the information technology design process can provide an opening to the tricky politics of incorporating academic disciplines into commercial research [see 6, 37, 39]. In this light, PARC and Weiser's strategy of evoking the social sciences and humanities can be understood as part of a broader story of manufacturing difference as a way of performing innovation that was unfolding in the USA at the time. The philosophers, social scientists and anthropologists of PARC become a valuable asset that adds to the company's cachet and is used to set its work apart from that of other similar technological centres distinguishing it from yet another 'pure engineering lab' [48]. This way, Weiser can respond to criticisms raised against ubiquitous computing's potential privacy and control risks (a story I will return to) with the argument:

Well, at PARC we have philosophers, social scientists, and anthropologists to offset the engineers; perhaps we could proceed with the work [of ubiquitous computing] while maintaining a dialogue about 
its uses. This would at least be an improvement over the naïve optimism of a pure engineering lab... [48].

At the same time, this becomes one of the moves (we will see that there are more) that constitute ubicomp as a figure that does innovation differently. Not just another engineering project that fusses with 'new widgets and gadgets' [30], ubiquitous computing is figured as different and important by its close association with these 'other' disciplines which, as the story goes, can not only offset the naïve engineers, but also direct innovation to what is really important in life 'away from emphasis on the machine and back to the person and his or her life in the world of work, play, and home' [45].

However, not everyone seems to have endorsed Weiser's figuration of ubiquitous computing. While he constructed ubicomp's exceptionalism as centred around the concept of invisibility, with the philosophical and anthropological foundations Weiser assigned to it, others seem to have focused more on the second key characteristic of ubiquitous computing, namely the idea of making computers ubiquitous. This drove Weiser to write in 1997 a personal email to Professor Hiroshi Ishii, the director of an MIT laboratory and the project 'Tangible Bits' requesting his help to 'stop the spread of misunderstanding of ubiquitous computing based simply on its name. Ubicomp was never just about making "computers" ubiquitous' [in 20]. Here, we see Weiser agonising about finding the appropriate label for his vision, and in the process giving us a valuable insight on the importance of a name:

I tried to stop using ubiquitous computing because of its misleading implication, but it keeps cropping up again, so I keep returning to it as my umbrella name for lots of work, including Things That Think. Augmented reality was in use for a while, but again got balkanized in meaning. I have started to talk about Calm Technology as a theme, but it better names a goal than a research project. "Tangible Bits" is very nice, and maybe could serve as an overall umbrella, but then you might lose it as the name of your research project! I think we would all benefit if we could have an allegiance to some one common thing, and define our difference within that. But we struggle with what to call that allegiance (in [20]).

Unfortunately, Weiser died two years later without having resolved this conundrum which seems to have troubled him until the end. As it is recalled in an obituary from the Department of Electrical Engineering and Computer Sciences, University of California, Berkeley (1999):

When he was diagnosed with cancer, he decided to spend his remaining time writing a book clearing up some of the confusion around ubiquitous computing.
Weiser wanted to sit by the seaside and write the book on the real essence of ubiquitous computing. 'They've completely missed the non-technical part of what ubiquitous computing is all about', he told Xerox's chief scientist and PARC's director, John Seely Brown (in [11]).

Regardless of Weiser's hesitations, as he himself had observed, the phrase ubiquitous computing (or ubicomp, in its most popular abbreviation) would prevail. And not only that, it would form, with the figure of Weiser himself, to whom I turn next, a close-knit association. The agonies and hesitations witnessed above have been folded and remain mostly hidden out of view and forgotten. They have been folded into a figure sturdy enough to become the basis of many other stories establishing, as we know, Weiser's vision of ubiquitous computing as the starting point of what came to be seen in some quarters as a new era in computing, and the progenitor of a number of projects that followed.

\section{Mark Weiser: Fathering ubiquitous computing}

In the paper 'The origins of ubiquitous computing research at PARC in the late 1980s', Weiser and his co-authors are keen to outline the many contributions that inspired and led to the emergence of the Ubiquitous Computing program in the Computer Science Laboratory (CSL) [51]. In most of his papers, however, this plurality of voices is moved to the background and Weiser's authorship becomes more prominent. A rhetorical move from a collaborative plural ('My colleagues and I at the Xerox Palo Alto Research Center [...] are trying to conceive a new way of thinking about computers' [43]) to a single authorship and authority 'I first created the idea of ubiquitous computing ...' ([46], or 'I call this future world "Ubiquitous Computing" [45]') presents and establishes Weiser as the father of ubiquitous computing who creates and names his creation.

As Wajcman argues, such figurations of sole, heroic male inventors are common in technoscientific origin stories [41]. Already familiar, due to their own origins in Christian patriarchal origin myths [19] or ancient Greek myths of god Zeus giving birth to an adult and fully clothed, fully armed Athena, this type of origin stories keep being repeated and re-appropriated (see, for example, [34]). These are storylines which flatten out and render invisible the polyphony of voices, influences, ideas, and potential problems and messiness that sometimes align in such a way as to bring about a new creation producing a simple and concise story instead [27].

In this case, through a process of sanitisation, or of distillation, Weiser also comes to be performed as the lone 
figure, the sole father-creator who labours and delivers his child-creation while colleagues, influences and problems get sidelined as 'extras', or as 'inspiration', only there to prop up and further support the main storyline as necessary. At the same time though, through this process of brainbirth, the child-creation, in our case ubiquitous computing, is also figured as new, singular and fixed, akin to the glorious and fully formed Athena; a creation that can be owned and, hence, mishandled, that can be known, and hence, misunderstood. So we see that the evocation of a troubled Weiser, as we saw earlier, who worries over the 'confusion' and 'misunderstanding' that surrounds ubiquitous computing and retreats to the seaside in order to write a book that lays out the 'real essence of ubiquitous computing' plays a dual role. It figures ubiquitous computing as singular and fixed, tied to Weiser the inventor to whom the creation is meant to 'belong', while at the same time it figures Weiser as the heroic, male inventor both blessed and burdened by the responsibility of his creation. And while this is one common way that innovation can be done, there are others which work in conjunction with this one.

Besides the sole heroic inventor, Weiser is also figured as a key part of a different corporation; namely, a corporation which under its director's motto that '[c]ompanies no longer assemble products so much as they make meaning out of the world' (Brown in [30]) is meant to be in the business of not merely producing new technologies but of continuously reinventing itself [4]. Consider, for example, the following extended quote:

I am honored to offer a few words of commentary on [the] columns by David Porush and Stephen DohenyFarina. First let me explain a little bit about Ubiquitous Computing, or Ubicomp, a technology I helped develop and one they mentioned concern about in their columns.

I weigh in as an engineer, someone whose primary interest is "what should I build next?" Ubicomp is an unusual project for an engineer, for two reasons. First, I took inspiration from anthropology; and second, I knew that whatever we did would be wrong. The anthropological critique was common in some quarters of Xerox PARC when I arrived in 1987. It went approximately like this: the most profound technologies are those that become embedded in people's lives; current computers force people to separate their machine life from the rest of their lives, so computers in their current form would never become a very significant or profound technology. [...], I took this as a challenge. Could I design a radically new kind of computer that could more deeply participate in the world of people?
This led me quickly to the second conclusion that I would get it wrong [48].

This is how Weiser starts an article titled 'The Technologist's Responsibilities and Social Change'. The article, which appeared in the Computer-Mediated Communication Magazine in 1995, came as a response to previous articles that appeared in the same magazine written by Stephen Doheny-Farina and David Porush, a professor of literature and an associate professor of technical communication, respectively, who raised serious concerns and criticisms about ubiquitous computing as a project because of its potentially grave consequences for issues such as privacy and control [8] [29]. Leaving for the moment the discussions on issues of privacy and control aside, I want here to suggest that it was not only ubicomp that was constituted as innovative and different. Weiser himself, as the head of the group and part of a corporation that claims to do innovation differently, had also to be seen to embody and perform this difference.

In her paper 'Consuming Anthropology', Suchman argues that in the case of information technology research and development, anthropology had a role not only as a social science (promising insights into worker and customer 'culture' and 'experience') but also as a brand ('offering human interest and public relations caché to corporate employers via the media') [39], and indeed, in the previous section of the paper we saw how anthropology and the social sciences and humanities more generally became constitutive in figuring ubiquitous computing as different, profound and new. Yet, there is more to the argument of anthropology as a brand to explore.

The main idea of corporate branding-namely that a successful brand should not only inform the relationship a company has with its customers through its products, but that it should also shape the company itself-resonates with the ethos that PARC, as part of Xerox, sought to embody under the management of John Seely Brown. As Brown writes in his article 'Research that reinvents the corporation', PARC was not only doing innovation in the traditional way by inventing new technologies and products, but, more importantly, it was in the business of doing innovation differently by investing in pioneering research, i.e. research that '[leads] us to redefine what we mean by technology, by innovation, and indeed by research itself' [4].

In this light, anthropology and the social sciences as a brand not only provided the company with an asset but they, in turn, would shape the company itself, in the sense that 'employees must 'live' the brand values in their dayto-day interactions' (Interbrand Insights in [26]). In this light, I read the extended quote above from Weiser's paper in the Computer-Mediated Communication Magazine as 
the result of his embodying, and being constituted as, a figure by the very ethos and values that the social sciences and humanities were supposed to carry as a brand. And so we see yet another story unfolding.

The figure of the sole heroic inventor is replaced here by one that displays a more collaborative stance. Ubiquitous computing turns from the invention Weiser creates and names to one that '[he] helped develop' [48] and so Weiser comes to embody one of Brown's mottos on the importance of 'coproducing innovation' [4]. At the forefront of innovation in PARC, the engineer is working side by side with the anthropologists. So, in this version of Weiser's story, PARC's anthropologists are not only attributed with the honour of providing the inspiration behind ubiquitous computing, but they are directly calling for a different approach to computing, one that, unlike personal computers, will become embedded in people's lives; in other words, as directly calling for ubiquitous computing. ${ }^{6}$

Following the title of his paper 'The Technologist's Responsibilities and Social Change' (1995), Weiser is figured here as the responsible technologist hovering between his deep-seated professional urge to take on 'a challenge' and a rather unexpected modesty and reflexivity about his professional abilities ('I knew that whatever we did would be wrong'). The devices-the tabs, pads and boards along with the active badges-become just the first step of a long and uncertain journey that extends well into the future and which Weiser has to make in order to meet the challenge of designing such a 'radically new kind of computer' [48]. At the same time, the machine is presented as a sort of co-producer that has the agency to transform its future user and so influence the process of innovation. As Weiser writes:

As I began to glimpse what such an information applicance [sic] might look like, I saw that it would be so different from today's computer that I could not begin to understand or build it. So I set out, instead, to build some things that my colleagues and I could put in use, things as different as we could imagine from today's computers, yet using technology that could be made solid today. Using these things would then change us. From that new perspective, I would then again try to glimpse our new kind of computer and try again [48].

In this storyline, the technologies which his critics saw as potentially dangerous become not a dubious product that PARC releases to the world, but an essential part of the

\footnotetext{
${ }^{6}$ As Weiser wrote: 'The anthropological critique was common in some quarters of Xerox PARC when I arrived in 1987. It went approximately like this: the most profound technologies are those that become embedded in people's lives ...' [48].
}

ongoing dialogue that Weiser wants to foster and encourage:

One possibility was to stop all such work immediately. Since we could see the potential for evil applications, why do it? And some individuals in the lab took this road. Others, including myself, continued the debate. Could we at PARC bring some special value to the work that others might not? [48]

Of course, the answer is meant to be 'yes' since, as we saw earlier, PARC has 'philosophers, social scientists, and anthropologists' whose 'special value' can offset the 'naive' engineers. And, hence, Weiser comes to embody Xerox's idea of 'reinvented innovation' by positioning himself as not-yet-another-engineer but, by courtesy of being part of a different corporation, as a responsible and socially aware technologist. One, who does not shy away from the difficult questions since, as he and his co-authors put it elsewhere, ' $[\ldots]$ in the end, it is hard to imagine a more important task for twenty-first century technologists' [51].

While the task of building a 'radically new kind of computer' is pushed well into the future becoming the vision of ubiquitous computing, at the same time it is imbued with a history-defining importance, courtesy of its association with Weiser who, in this story, is figured as the model of the different or enlightened engineer of the twenty-first century. $\mathrm{He}$ is the technologist who comes to embody the break between the old ways of doing innovation, and the new ones heralded by a 'reinvented' Xerox PARC and its exciting, multidisciplinary team. Once again, the figure of Weiser becomes integral to the ways that ubicomp is figured as different and important. This configuration is nicely captured in the words that Brown wrote as an epilogue to Weiser's posthumous paper.

As this brief essay describes, [Weiser's] vision of ubiquitous computing transcends the issues raised by technology and searches for ways to redefine how we relate to each other [...] For Mark, sharp boundaries between the social and the technical, between the artistic and the scientific, and between work and play never existed. He sought to create a technological world that honored the human and social spirit (Brown in [51]).

Here ubicomp is figured as different and profound, courtesy of its charismatic and revolutionary creator while, at the same time, one sees that the two figurations explored in this section-Weiser as the creator and inventor, and Weiser as the collaborator and the multidisciplinarian-are not at odds. Instead, they complement each other in ways that strengthen the ubicomp configuration and reconfirm its exceptionalism. 


\section{The vision: time lines, pasts and futures}

'[U]bicomp, in my mind, has the routes [sic] in the community that was... well, in the 90s working on handheld devices and sensors and it was a mix of ah, systems community and kind of HCI community... many people have positioned ubicomp as something that comes after mobility... so you know, we're in the mobile era but we'll get to the ubicomp era. Um... but somehow that doesn't fit it either, I mean there is the... Mark Weiser's paper which ah... one, these days, almost gets annoyed with how often it gets quoted, you know, it's the first sentence of each paper I review... like - yes [in begrudging voice], yes that's disappearing technologies and all of that... but I think the reality is slightly different' (Mirjana Spasojevic, Nokia Research Centre, Palo Alto trying to describe what ubicomp is, in [22]).

Traweek writes that '[a] community is a group of people who have a shared past, hope to have a shared future, have some means of acquiring new members, and have some means of recognizing and maintaining differences between themselves and other communities' [40]. Weiser's vision of ubiquitous computing did not disappear after Weiser's death. Instead, it was taken up by a number of researchers constituting themselves as the ubicomp community, and it seems that, regardless of the way these different researchers have chosen to respond to Weiser's vision, he and his Scientific American article have become an obligatory citation in the field of ubiquitous computing.

The figure of a vision of a future technological world then becomes the third component, along with the figure of ubiquitous computing and the figure of Weiser, of what I have come to see as the ubicomp configuration. In this final section, I investigate how specific temporal moves have become constitutive of the ubicomp configuration by focusing first on the past and the histories of ubiquitous computing, and then to the futures that are folded within the figure of its vision.

\subsection{Past time lines}

Latour writes that ' $[t]$ ime is not a general framework but a provisional result of the connection among entities' [24], so this result can be made and remade in different ways. Rich Gold gives us an insight into how he and his colleagues in PARC made time:

The future doesn't actually yet exist. It's a story that we tell ourselves to help us get up in the morning and moving in the right direction. Events can rapidly alter that future [...]. When we designed the first ubiquitous computing artefacts, for instance, there was no World Wide Web. Its sudden appearance made our work look as if it was heading in the wrong direction, as if it was following the wrong story. And so we created a new story about the past and now it fits perfectly. It is not just the future that doesn't exist; neither does the past [12].

So, what kind of past did they create?

While writing about modern timelines, histories and alternative temporalities, Latour tells us that '[i]t is the sorting that makes the different times, not the times that make the sorting' [24]. In the Scientific American paper, Weiser sorts out the past using his own founding premise as an end-goal, a telos; namely, the premise that '[t]he most profound technologies are those that disappear. They weave themselves into the fabric of everyday life until they are indistinguishable from it' [43]. On that basis, Weiser creates a genealogy of key technologies-writing, electricity, motors - which he reads through his own premise to confirm (in a circular way) its validity [43]. This genealogical list is sorted so as to logically lead to the latest addition, ubiquitous computing, building in a discursive manner a time line that reaches its goal with this project. And this is what makes this type of storytelling plausible, namely 'the fact that one thing leads discursively to another. Somehow or other, events go together, distributed onto a line, a time line, line of influence, the teleological means-ends line that is the guiding thread of a project' [25].

According to Law, genealogy, the tracing of descent, is one of the strategies for making a project. In other words, narrating the world as genealogy, as 'a plausible historical narrative, a plausible origin story' is a trope, a method of distributing or coordinating things in a way that says what exists or not, or, in our case, what goes with or does not go with, what else [25]. It is a way of making similarities and differences. And, as we have seen, manufacturing difference is one of the key moves of figuring innovation, in general, and ubiquitous computing, in particular.

As Gold writes, ubiquitous computing had to compete with other technological stories which were circulating at the time, such as stories about the World Wide Web, virtual reality and software agents which had no place for ubicomp itself [12]. With this in mind, I read Weiser's genealogical account as a strategy that sought to coordinate things in such a way as to create a difference, and to distribute value in such a way as to discredit those who find themselves on the wrong side, by measuring them against ubicomp's founding premise only to find them wanting:

Silicon-based information technology $[\ldots]$ is far from having become part of the environment. [...] The arcane aura that surrounds personal computers is not 
just a 'user interface' problem. My colleagues and I at the Xerox Palo Alto Research Center think that the idea of a 'personal' computer itself is misplaced and that the vision of laptop machines, dynabooks and 'knowledge navigators' is only a transitional step towards achieving the real potential of information technology [43]. ${ }^{7}$

Refuting any lineages with past and ongoing computing projects, or reducing them merely to a transitional step, is a figurative move that seeks to clear the ground in order to more securely nest Weiser's own vision of ubiquitous computing as the ultimate goal, the 'real potential of information technology' [43]. And this move appears to work on two levels. On the one hand, by separating ubiquitous computing from other 'present-day trends' [43], as Weiser calls them, while lumping the latter all together as misguided within this genealogy, ubiquitous computing is figured as different, courtesy in this case, not of its intellectual foundations, but of its special lineage and ancestors. On the other hand, by relating ubiquitous computing to time-enduring technologies such as writing and electricity, it is figured not only as different, but also as right, namely the right vision which will withstand the test of time among all those competing and misguided ones.

In another context, the (hi)story changes and technologies such as the personal computer, the dynabook and the knowledge navigator are not presented as transitional steps towards technology's 'real goal', but as the 'beaten track' that ubiquitous computing stays well clear of, heading in almost the opposite direction (Weiser illustrates this with a diagram of two diverging lines [44]). And elsewhere the story changes yet again, as ubiquitous computing's history drops the fluidity and sense of continuity that the diverging lines of the Weiser's diagram conveyed [44] and becomes more clean-cut and schematic. It comes in different waves [49] or differing trends, phases or eras [50] and has provided the blueprint for what came to be seen as Weiser's established history of ubicomp as the third wave of computing. In this story, the Internet replaces the PC as the transitional step (while the latter is assigned to its own era) in order to accommodate the public appearance of the Internet and the World Wide Web which, as Gold earlier told us, drove PARC to create 'a new story about the past [which] now [...] fits perfectly' [12].

Indeed, Gold appears to have known all too well that work and effort is needed to put such time lines together, however familiar they might appear now, in order to make things fit and create the 'right' story; even if sometimes the result would be less than perfect, revealing through its

\footnotetext{
7 This misguided genealogy, according to Weiser, also includes projects such as mobile computing, multimedia computing, artificial intelligence and, last but not least, virtual reality.
}

clumsiness that things do not naturally fall together. Instead, some force and energy is behind such efforts to bring things together and hold them there in an effort to make history. Yet while all these different stories and different genealogies constantly shift and shape themselves to fit the circumstances, what remains constant is the task for each of them to represent ubiquitous computing as either the telos, the destination of the development of technological history, i.e. the place where things are heading, or the different development that challenges the mainstream, 'beaten track', i.e. the place where things should be heading.

The ubicomp community has indeed embraced Weiser's origin story and its time line which, in all its versions, directs history towards the vision of ubiquitous computing. Such an endorsement not only further strengthens the figure of ubicomp, but also becomes central in performing the ubicomp community itself, since the figure of ubicomp with its father, its history and its future vision comes to provide the shared past, expectations for a shared future, and ways of making difference that, as Traweek earlier stated, are the key elements in constituting a community. This then means that the ubicomp community has a stake in the preservation and continuation of the ubicomp figuration, since it provides the framework within which this community can exist and make sense. Therefore, it is essential for the ubicomp community to keep working with and on this figuration in order to maintain it by ironing out inconsistencies and by folding in differences in order to make things fit. ${ }^{8}$

In this light, constant references to the same paper, besides being repetitive and frustrating (as the opening quote of this section demonstrates), are also tools for making and sustaining genealogy and lineages by strengthening ties and maintaining similarities while, at the same time, ironing out differences and inconsistencies. And it is no wonder that Abowd himself admits that whenever he is having trouble explaining what ubicomp is, he 'falls back' to the familiar and recognisable definition provided in Weiser's 1996 paper [1].

In these kinds of stories, there cannot be new without old, and similarly, there cannot be a future without its past. Rich Gold's earlier quote gave us a sense of the role stories play in creating pasts and futures, and we saw that a past can be crafted and recrafted in such a way as to create the appropriate set up for the appearance and continuation of ubiquitous computing. A past has to be narrated, documented and archived, shaped and appropriated, or in other

\footnotetext{
${ }^{8}$ For example, contra to Weiser's articulations, the role of small networked portable computer products, such as smart phones and personal digital assistants (PDAs), has been reconceptualised and such devices are now considered part of the era of ubiquitous computing (see [42]).
} 
words to be consumed and become history, for the new to take its place and for the clock to strike 'post-PC' time. And it is in this kind of set up that visions can appear and become credible. Trends appear, peak and eventually fade away and die. And this is not meant to be Weiser's or anyone else's doing. It is, as this story goes, the natural order of things.

So from crafted breaks, historical step changes and revolutions, new and exciting things are meant to spring. Future possibilities of new and better things. And this is the set up where the vision of ubiquitous computing appears.

\subsection{Future visions}

Bell and Dourish start the abstract of their article 'Yesterday's tomorrows: notes on ubiquitous computing's dominant vision' as such:

Ubiquitous computing is unusual amongst technological research arenas. [...] It is driven ... not so much by the problems of the past but by the possibilities of the future [3].

Indeed, as the authors write, not only the title of his foundational article, 'The Computer for the twenty-fist Century' (1991), but also the rhetorical tone that Weiser adopted in this article were to be an invitation for his readers to cast an eye to the future that he and his colleagues were preparing. And many not only accepted the invitation to somehow contribute to the coming of this future world, but also adopted Weiser's rhetorical tone which, according to Bell and Dourish, was characterised by its invocation to a "proximate future, one "just around the corner", [3], see also [9]). So much so, that the authors write:

In fact, citations to Weiser's article are often phrased not so much as a "look backwards" but rather as a collective "look forwards"; that is, instead of saying "back in 1991, we thought that...", they say "Just as Weiser suggested in 1991, we are soon to enter a world where..." [3].

Bell and Dourish rightly highlight the central role that future technological possibilities play in ubiquitous computing's constitution (especially considering that we still talk about the 'vision' of ubiquitous computing). However, as we will see, there is more to ubicomp's relationship with the future than the idea of the 'proximate future' captures.

The ubicomp community has, in some form or other, embraced Weiser's origin story, accepting and reiterating ubicomp's history, while it also actively participates in this history's performance by accepting Weiser's vision and setting off in a quest for its fulfilment (and so, in turn, enacting itself as a community). And it is in this quest that the Scientific American paper becomes a landmark in the community's history, not only as an obligatory node in the history of ubiquitous computing; a point from where Weiser's vision unfolds all the way to the future, but also as the material incarnation of the moment when the creator shares his vision with his future disciples. Or, in other words, the moment when the future is revealed in front of the eyes of everyone present and willing to see. To better understand this, I see this story as part of a bigger one. A (hi)story that runs through the hi-tech laboratories of Silicon Valley in the 1980s and 1990s.

The Xerox PARC brand was part of this mythic 'technoscape' which, as Suchman writes, was figured as the place that operates as a 'vanguard, with its attendant mandate to enact the future that others will subsequently live' [37]. In this context, the publication of Weiser's paper in the popular science magazine Scientific American, with its visionary title and its pictures of Weiser and other computer scientists sitting on the cosy sofas and beanbags of PARC's meeting rooms surrounded by coffee mugs, papers and a range of new devices served a double purpose. Not only an insight into the work that takes place in PARC's laboratories, but also a precious glimpse at the future that is brewing inside them and a proof that, as the Silicon Valley technologist declared on the radio one evening around 1995, 'the future arrives sooner here' (see [37]).

Key to this performance are the prototypes that Weiser presents in his paper, the artefacts themselves, which came to embody PARC's early maxim of 'build what you use, use what you build.' But with a difference. A WIRED article states that 'this now hoary PARC wisdom' was the motto Bob Taylor established when he was the director of PARC's computer science laboratory [30]. Weiser, as new laboratory director, offered his own reading:

One of the first things Mark Weiser shared was his own interpretation [...]: "You let what you build change you, and you move on." In Weiser's view, PARC learns how to build better tools, and then everybody learns to use them. Then they do it all again, with the new tools [30].

While paying his respects to PARC's history, Weiser is also keen as the new director of the laboratory to be seen making his mark by leading the laboratory forward and away from its past glories or current problems. His interpretation of Taylor's motto introduces a movement and a hierarchy; PARC charges towards the future and everyone follows. The tools, as I have shown elsewhere, are not the end-goal, but the means to assist PARC's journey towards the future and its ultimate goal, a world of ubiquitous computing, as well as the material manifestation that PARC is already one step ahead. 
This is the story that the prototypes tell in Weiser's seminal paper. Depicted as casually scattered around the computer scientists while they (in the plural, unlike the image of the sole user of the personal computer) collaborate, discuss and focus on the task at hand, the prototypes, with their casual and inconsequential presence, are there to tell the story of ubiquitous computing embodying Weiser's premise that ' $[\mathrm{t}]$ he most profound technologies are those that disappear' [43]. These prototypes were the components of the 'experimental embodied virtuality' which, just like Taylor's maxim dictated, Weiser and his colleagues sought to build and test out in PARC with themselves serving 'as guinea pigs' [43].

But apart from the significance of the prototype to the practices of engineering, as a way to build robust technologies, these artefacts are also there to perform innovation and to embody new technological possibilities not yet available in the market. Weiser's exciting descriptions of the ways that the computer scientists in PARC use these prototypes - 'doors open only to the right badge wearer, rooms greet people by name, ...'-along with the casualness with which these artefacts are supposed to have been incorporated in PARC's everyday life- 'We have built enough live boards to permit casual use: they have been placed in ordinary conference rooms and open areas, and no one need sign up or give advance notice before using them' [43] - become declarations that the future is already happening here, in PARC.

But this is not the whole story. Earlier I showed that Weiser's interpretation of PARC's early maxim is one that introduces a movement, a continuous passing of time. 'You let what you build change you, and you move on' (Weiser in [30]) to future and better things. In that sense, the moment that the prototypes perform innovation, they also perform a kind of obsolescence which constitutes this sense of movement, since by the moment we, the readers, catch a glimpse of the future brewing in its laboratories, PARC is supposed to have already moved on to the next thing in its pursuit of the ubicomp vision. As Bell and Dourish ([3], see also [9]) have already identified, this constant deferral to the 'proximate future' down the line is one of the moves that constitutes the vision of ubiquitous computing as always coming, around the corner, and at the same time, as always fresh and new, while keeping PARC always one step ahead of everyone else. Weiser tells us this when he proclaims that these prototypes are 'just the beginning of ubiquitous computing' [43] and when, in another paper, he calls this prototyping stage the Phase I of ubiquitous computing [45]. The glimpse of the future that the Scientific American paper provides has already come to pass for PARC, since its computer scientists have probably already moved on to Phase II, III, etc. Weiser guides the reader's attention away from the artefacts themselves and down the horizon of future possibilities where his vision is supposed to reside. He tells us: 'The real power of the concept comes not from any one of these devices-it emerges from the interaction of all of them' [43]. But for this interaction to materialise, for us to be able to witness the 'real power of the concept', there are other technological developments that need to come about [43].

In the paragraphs that follow, Weiser outlines step by step the way that his constructed time line will unfold in the future and towards his vision. So he writes with an anticipated certainty presenting with the confidence of an insider the technologies that appear to be just down the line, only to move on to developments not yet pipelined, way beyond the 'proximate future', which will have to take place in order for the vision of ubiquitous computing to become reality, thus setting a technological agenda that stretches further along his future time line. And finally, as if humbled by the profundity of his own vision, while implicitly prefiguring a successful future for ubiquitous computing stretching centuries away, Weiser states:

Neither an explication of the principles of ubiquitous computing nor a list of the technologies involved really gives a sense of what it would be like to live in a world full of invisible widgets. Extrapolating from today's rudimentary fragments of embodied virtuality is like trying to predict the publication of Finnegans Wake shortly after having inscribed the first clay tablets [43].

All these statements work in conjunction to figure ubicomp and Weiser in particular ways. The first is the implied sense that the creator needs to let go in order for the vision to realise its full potential. The 'real power of the concept' is imagined as profound, yet unimaginable, and hence, it is performed as impossible to be captured by even the great minds of PARC. Ubiquitous computing is performed as a vision that is beyond the here and now and the only thing that the proud yet modest creator can do is to offer it to the world. At the same time, even while claiming that it is impossible to foresee how the ubicomp vision will unfold, Weiser directs our imaginations down a very particular route.

Using the analogy of writing technology with its centuries-long history and its profound impact on our civilisation, he prefigures an analogously successful and profound future for his own vision. The vision now appears also as contained, controlled and limited to a prefigured path that is meant to stretch for centuries, while Weiser appears as the anxious and demanding father who predetermines a specific path of certain success for his childvision. And so we see another move that constitutes the vision of ubiquitous computing, no longer as only fresh and new and always evolving, but also as controlled and contained. 
This reading of innovation discourse aligns with Suchman's account of her experience of PARC's efforts during the mid-1990s to turn the imperative of innovation to itself, in an exercise that required its employees to reinvent themselves, along with the corporation, into something new [37]. In her project that interrogates the category of the new by tracing how innovation is enacted through multiple and particular performances, Suchman reflects back on the ways PARC sought to apply specific innovation practices to its workings that were, frustratingly for some of its employees, caught between 'a commitment to openness and flow on one hand, and an investment in objects with definite and fixed boundaries, separable from their surroundings, on the other' [37]. As she writes: 'contra the widely accepted narrative, [...] a site such as PARC is designed in important respects systematically to block innovation, if by the latter we understand a kind of ongoing or unfolding transformation' [37].

Indeed, Grosz writes about a common and widespread anxiety in the face of an indeterminate and unpredictable future, and a desire for the old to contain the new in a state of 'predictable transformation, transformation which follows a predesignated path, innovation within legitimised parameters, that is, controlled and regulated progress' [15]. Weiser's motto of 'you let what you build change you, and you move on' may present a progressive albeit carefully controlled transformation, but it leaves too much at stake in the more distant future. As Grosz writes, unpredictable movement and transformation may involve mutation and metamorphoses 'with implications or consequences which cannot be known in advance' [15], or in other words, it might mean changes beyond the control of the author and inventor.

What follows then in Weiser's article is a fictional scenario describing the life of Sal, the Silicon Valley professional (and notably the only woman technologist we have encountered so far in these stories) who we briefly met at the beginning of this chapter and who lives in the world of ubiquitous computing.

Sal awakens; she smells coffee. A few minutes ago her alarm clock alerted by her restless rolling before waking had quietly asked, "Coffee?" and she had mumbled, "Yes." "Yes" and "no" are the only words it knows [43].

Sal's story is supposed to bring the ubicomp world alive. It frames the future in ubicomp terms in such a way as to make this particular version of the future imaginable, and hence desirable, while at the same time it lays down and prefigures a path of technological development that extends well into the future. As Kinsley writes,

it is through the imaginative framing of the future 'everyday life' of the character Sal that readers 'knew' what it would be like to live with ubicomp. [...]. This anticipatory knowledge of ubicomp facilitated the easy communication of a system of research themes [...], while also propagating an orientation towards a time in which such forms of technical encounter would be possible [23].

Weiser tells us the story of Sal at the same time as he writes the story of his vision and invites his readers to follow him down his time line and towards that future. And many have complied. The ubicomp community's mission statements, as we saw them earlier, are an attempt to 'move closer' to Weiser's vision [2], or to 'reach' for this vision [31], and its retrospectives examine, more than 20 years after this vision's first articulations, 'how far toward Weiser's vision we have come' ([7]; my italics), or where the scientific community should go next 'as the quest to attain Weiser's vision continues' [10]. This adopts and preserves ubicomp's figuration as the singular, preformed destination at the end of a prefigured linear future time line; a time line that the ubicomp community has to merely follow in order to reach its destination, rather than to actively and messily build into existence.

But, as I have demonstrated before, such an endorsement not only makes time by preserving and maintaining this particular temporal arrangement, but, in turn, it also performs community; a community that shares past, future, a father figure and a common goal. Hence, even when these retrospectives reveal that some things might not have worked out as Weiser predicted, and in some cases they have actually taken the opposite form, the main narrative of a path laid down by Weiser, and this one history, continues to be repeated and maintained. ${ }^{9}$

\section{Conclusion}

Responding to ubicomp's multiple and messy nature, this paper moved away from questions of reference-what is ubiquitous computing? What is the history of ubiquitous computing? Instead, following the call manifested in feminist STS, it attended to questions of relational processes-how is ubiquitous computing figured in particular (hi)stories, practices and knowledges?

Specifically, using the descriptive and methodological tool of configuration, this paper explored ubicomp as a

\footnotetext{
${ }^{9}$ See, for example, Schmidt et al. who write "mobile phones - and increasingly other portable devices, such as pads and tablets - have become ubiquitous and, at the same time, very personal. This trend is in contrast to one of Weiser's forecasts' (25-26) only for a few pages later to declare: 'Reflecting on Weiser's visions 20 years later, it's amazing how the vision foresaw many technological developments that have fundamentally changed how we interact with computers and how we communicate' [32].
} 
configuration that comprises three key figures: ubiquitous computing as a name and a term, Mark Weiser who came to be identified as the father of ubiquitous computing, and finally the temporalities folded within ubicomp's 'vision'; all three figures tightly interwoven under the phrase, Weiser's vision of ubiquitous computing. By unpacking each figure and carefully attending to the processes that hold the configuration together, this paper made visible the frictions and contradictions that ubicomp folds within it, while, at the same time, it attended to the practices that help the whole configuration to circulate, become dominant and productive. This way, it sought to resist and intervene to the reductive dominance of ubicomp's origin history and attend, instead, to ubicomp's multiple and messy nature and (hi)stories in order to open up ways that it can be reconfigured differently [35].

Open Access This article is distributed under the terms of the Creative Commons Attribution 4.0 International License (http://crea tivecommons.org/licenses/by/4.0/), which permits unrestricted use, distribution, and reproduction in any medium, provided you give appropriate credit to the original author(s) and the source, provide a link to the Creative Commons license, and indicate if changes were made.

\section{References}

1. Abowd G (2012) What next, ubicomp? Celebrating an intellectual disappearing act? Paper presented in UbiComp'12. http://ubicomp. cc.gatech.edu/papers/whatsnext-ubicomp2012.pdf. Accessed 20 Dec 2015

2. Abowd G, Brumitt B, Shafer S (2001) Preface. In: Abowd G, Brumitt B, Shafer S (eds) Ubicomp 2001: ubiquitous computing, LNCS 2201. Springer, Berlin, pp V-VI

3. Bell G, Dourish P (2007) Yesterday's tomorrows: notes on ubiquitous computing's dominant vision. Pers Ubiquit Comput 11(2):133-143

4. Brown JS (1991) Research that reinvents the corporation. Harv Bus Rev 69(1):102-111

5. Castañeda C (2002) Figurations: child, bodies, worlds. Duke University Press, Durham

6. Cefkin M (ed) (2010) Ethnography and the corporate encounter: reflections on research in and of corporations. Berghahn, New York

7. Davies N (2012) Twenty years on. IEEE Pervasive Comput 11(1):2-3

8. Doheny-Farina $S$ (1994) Default $=$ offline, or why ubicomp scares me. Comput Mediat Commun Mag 1(6):18. http://www.december. com/cmc/mag/1994/oct/last.html. Accessed 20 Dec 2015

9. Dourish P, Bell G (2011) Divining a digital future: mess and mythology in ubiquitous computing. MIT Press, Cambridge

10. Ferscha A (2012) 20 years past Weiser: What's next? IEEE Pervasive Comput 11(1):52-61

11. Galloway A (2004) Intimations of everyday life ubiquitous computing and the city. Cult Stud 18(2\&3):384-408

12. Gold R (2007) The plenitude: creativity, innovation and making stuff. MIT Press, Cambridge, MA

13. Gold R (2008) The plenitude: a companion. MIT Press, Cambridge. http://www.scribd.com/doc/3250926/The-Plenitude-ACompanion. Accessed 20 Dec 2015
14. Greenfield A (2006) Everyware: the dawning age of ubiquitous computing. New Riders, Berkley

15. Grosz EA (1998) Thinking the new: of futures yet unthought. Symploke 6(1-2):38-55

16. Haraway D (1988) Situated knowledges: the science question in feminism and the privilege of partial perspective. Fem Stud 14(3):575-599

17. Haraway D (1991) A cyborg manifesto: science, technology, and socialist-feminism in the late twentieth century. In: Idem, Simians, Cyborgs and Women: the reinvention of nature. Free Association, London, pp 149-182

18. Haraway D (1994) A game of cat's cradle: science studies, feminist theory, cultural studies. Configurations 2(1):59-71

19. Haraway D (1997) Modest_Witness@Second-Millennium. Femaleman_Meets_Oncomouse: feminism and technoscience. Routledge, New York

20. Ishii H (2004) Bottles: a transparent interface as a tribute to mark Weiser. IEICE Trans Inf Syst 87(6):1299-1311

21. Kember S (2003) Cyberfeminism and artificial life. Routledge, London

22. Kinsley S (2010) Practising tomorrows? Ubiquitous computing and the politics of anticipation (PhD dissertation, University of Bristol). http://www.samkinsley.com/pdf/kinsley_thesis_web.pdf. Accessed 20 Dec 2015

23. Kinsley S (2012) Futures in the making: practices to anticipate 'ubiquitous computing'. Environ Plan A 44:1554-1569

24. Latour B (1993) We have never been modern. Harvard University Press, Cambridge

25. Law J (2002) Aircraft stories: decentering the object in technoscience. Duke University Press, Durham

26. Lury C (2004) Brands: the logos of the global economy. Routledge, Oxford

27. MacKenzie D, Wajcman J (1999) Introduction. In: MacKenzie D, Wajcman J (eds) The social shaping of technology, 2nd edn. Open University Press, Buckingham, pp 3-27

28. Mol A (2002) The body multiple: ontology in medical practice. Duke University Press, Durham

29. Porush D (1995) Ubiquitous computing vs. radical privacy: a reconsideration of the future. Comput Mediat Commun Mag 2(3):46. http://www.december.com/cmc/mag/1995/mar/last.html. Accessed 20 Dec 2015

30. Rheingold H (1994) PARC is back. WIRED 2.02. http://www. wired.com/wired/archive/2.02/parc_pr.html. Accessed 20 Dec 2015

31. Satyanarayanan M (2002) A catalyst for mobile and ubiquitous computing. IEEE Pervasive Comput 1(1):2-5

32. Schmidt A, Pfleging B, Alt F, Sahami Shirazi A, Fitzpatrick G (2012) Interacting with 21st century computers. IEEE Pervasive Comput 11(1):25-31

33. Smith DK, Alexander RC (1999) Fumbling the future: how Xerox invented, then ignored, the first personal computer. iUniverse

34. Sofia Z (1998) The mythic machine: gendered irrationalities and computer culture. In: Bromley H, Apple WA (eds) Education/ technology/power: educational computing as a social practice. State University of New York Press, Albany, pp 29-51

35. Suchman L (2007) Human-machine reconfigurations: plans and situated actions, 2nd edn. Cambridge University Press, Cambridge

36. Suchman L (2007) Feminist STS and the sciences of the artificial. In: Hackett E, Amsterdamska O, Lynch M, Wajcman J (eds) The handbook of science and technology studies, 3rd edn. MIT Press, Cambridge, pp 139-163

37. Suchman L (2011) Anthropological relocations and the limits of design. Annu Rev Anthropol 40:1-18

38. Suchman L (2012) Configurations. In: Lury C, Wakeford N (eds) Inventive methods: the happening of the social. Routledge, London, pp 48-60 
39. Suchman L (2013) Consuming anthropology. In: Barry A, Born $G$ (eds) Interdisciplinarity: reconfigurations of the social and natural sciences. Routledge, London, pp 141-160

40. Traweek S (1988) Beamtimes and lifetimes: the world of high energy physicists. Harvard University Press, Cambridge

41. Wajcman J (1991) Feminism confronts technology. Polity Press, Cambridge

42. Want $\mathrm{R}$ (2010) An introduction to ubiquitous computing. In: Krumm J (ed) Ubiquitous computing fundamentals. Chapman \& Hall/CRC Press, Boca Raton, pp 1-36

43. Weiser M (1991) The computer for the 21st century. Sci Am 265(3):94-104

44. Weiser M (1992) Does ubiquitous computing need interface agents. In: Presentation given at MIT Media Lab symposium on user interface agents. http://www.ubiq.com/hypertext/weiser/ WeiserPapers.html. Accessed 12 May 2007

45. Weiser M (1993) Some computer science issues in ubiquitous computing. Commun ACM 36(7):75-84
46. Weiser M (1993b) Ubiquitous computing. In: IEEE computer "Hot Topics". http://www.ubiq.com/hypertext/weiser/UbiCom pHotTopics.html. Accessed 20 Dec 2015

47. Weiser M (1994) The world is not a desktop. Interactions 1(1):7-8

48. Weiser M (1995) The Technologist's responsibilities and social change. Comput Mediat Commun Mag 2(4):17. http://www.decem ber.com/cmc/mag/1995/apr/last.html. Accessed 20 Dec 2015

49. Weiser M (1996) The open house. ITP Review 2.0. http:// makingfurnitureinteractive.files.wordpress.com/2007/09/whole house.pdf. Accessed 20 Dec 2015

50. Weiser M, Brown JS (1996) The coming age of calm technology. http://www.ubiq.com/hypertext/weiser/acmfuture2endnote.htm. Accessed 20 Dec 2015

51. Weiser M, Gold R, Brown JS (1999) The origins of ubiquitous computing at PARC in the late 80s. Pervasive Comput 38(4):693-696 